University of North Florida

UNIVERSITY of

NORTH FLORIDA.

UNF Digital Commons

Public Health Faculty Publications

Department of Public Health

$11-4-2013$

\title{
Rural Breast Cancer Patients and Survivors Perspectives using Online Health Resources
}

Julie W. Merten

University of North Florida, jmerten@unf.edu

Kim Walsh-Childers

Lakeisha Rodman

Mary Ellen Young

Natalie Birchwood

Follow this and additional works at: https://digitalcommons.unf.edu/hhea_facpub

Part of the Public Health Commons

\section{Recommended Citation}

Merten, Julie W.; Walsh-Childers, Kim; Rodman, Lakeisha; Young, Mary Ellen; and Birchwood, Natalie, "Rural Breast Cancer Patients and Survivors Perspectives using Online Health Resources" (2013). Public Health Faculty Publications. 4.

https://digitalcommons.unf.edu/hhea_facpub/4

This Article is brought to you for free and open access by the Department of Public Health at UNF Digital Commons. It has been accepted for inclusion in Public Health Faculty Publications by an authorized administrator of UNF Digital Commons. For more information, please contact Digital Projects.

(C) 11-4-2013 All Rights Reserved

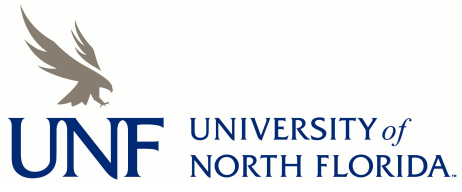




\section{Rural Breast Cancer Patients and Survivor's Perspectives using Online Health Resources}

\author{
Julie Williams Merten ${ }^{1 *}$, Kim Walsh-Childers ${ }^{2}$, Lakeisha \\ Rodman $^{2}$, Mary Ellen Young ${ }^{3}$ and Natalie Birchwood ${ }^{1}$
}

\begin{abstract}
Background: Breast cancer is the second most common cancer in women, with over 2.5 million breast cancer survivors in the United States. These patients, survivors and their loved ones use the Internet to find information about breast cancer, search for treatment options and connect with support groups. For women in medically underserved areas, especially rural areas, the Interne could be one of their only sources of information.

Objective: The study investigates rural breast cancer patients and survivors' motivations to seek online information, ability to use the Internet as a health information source, barriers to finding the information they seek, and the search strategy they use when seeking information online.

Methods: This qualitative study used "think-aloud" interviews with rural breast cancer patients and survivors to examine the thought process used to select online breast cancer information. Data were analyzed using thematic analysis in NVivo 9.

Results: Patients use Internet searches to corroborate provider recommendations and treatment plans. They preferred websites affiliated with nationally recognized cancer centers and breast cancer support organizations with few advertisements and comprehensive information.

Conclusions: The importance of trust within the provider-patient relationship is a core theme. Although the provider is the preferred source of information, patients will use the Internet to verify provider recommendations.

Implications for Practice: Rural breast cancer patients desire Internet search training. Nurses and breast cancer survivors would be effective trainers to increase patient online search information satisfaction and provide reliable resources for patients seeking accurate health.
\end{abstract}

\section{Introduction}

The transition from the healthcare provider, books, TV and friends serving as the primary sources of information has shifted to the Internet [1] with $95 \%$ of adults reporting the Internet is a "valuable tool for health information" [2]. The Internet provides an information source that is always accessible [3], constantly updated and a sense of privacy for sensitive health information searches [4]. The problems with Internet sources are the reliability and accuracy of information. The Internet has transformed the health information seeking process, especially among those living with chronic disease conditions like

*Corresponding author: Julie Williams Merten, MSH, MCHES Department of Public Health, University of NorthFlorida, 1 UNF Drive, Jacksonville, FL 32224 USA, Tel: (904) 620-4017; E-mail: JMerten@unf.edu

Received: May 04, 2013 Accepted: October 29, 2013 Published: November 04, 2013 breast cancer. High-speed connections, smartphone applications and social networking sites have further changed the information search process. The Internet provides the opportunity for patients to learn more about their conditions better prepare for the healthcare process and make more informed treatment and management decisions [5].

Breast cancer is the second most common cancer diagnosed in women in the United States [6]". According to the National Cancer Institute, an "estimated 226,870 women were diagnosed with cancer of the breast in 2012 [7]". In addition, approximately 2.9 million US women with a history of breast cancer were alive in January 2012 [8]. Breast cancer patients demonstrate higher usage of quality websites [9] than others with chronic diseases. Although the Internet is popular for health information seeking, people still strongly favor their health professional as their preferred source of information [10]. Among chronic disease sufferers, cancer patients are the most active online and cancer is among the top two diseases searched online [11]. Breast cancer is one of the most searched cancers [12] and overall, the breast cancer websites have shown better credibility than other diseases [13]. The Internet has provided opportunities for patients to learn more about their condition, access clinical trials, research alternative treatments, connect with other cancer patients and clarify information learned from healthcare providers [14,15]. Google Trends, a search history trends feature, has also found spikes in search volumes specific health-related terms [16]. When a celebrity announces they are being treated for a certain medical condition, there is a significant correlation between the celebrity and medical condition search volumes [17].

For women living in rural areas, particularly those from lowincome families, obtaining access to high quality breast cancer information, the digital divide, may be particularly problematic because there may be few locally available sources for cancer information [18]. Additionally, women living in rural areas are more likely to experience the "digital divide", with less access to communication and information technology [18]. Based on their review of 41 studies of rural breast cancer survivors' experiences, Bettencourt et al. [19] concluded that, compared to urban women, rural breast cancer survivors are less satisfied with the medical support, including informational support, they receive after primary treatment ends because they have less access to local doctors and because, even when local doctors are available, those doctors may be less current in their oncology care knowledge. Bettencourt et al. concluded that rural breast cancer patients want more access to health information both during and after primary treatment; few rural women receive information that is specifically targeted to them and addresses the unique challenges rural women face [19]. Wilson et al. [20] have argued that increased access to accurate information, as well as support from other survivors will be especially important in improving the quality of life for rural breast cancer survivors.

Williamson found that breast cancer patients reported problems sorting through the huge volume of information and in determining the quality of online information [21]. Peterson et al. report similar findings from a qualitative study investigating consumers' use of online information on medicines [22].

Based on their analysis of a random sample of published research 
Citation: Merten JW, Walsh-Childers K, Rodman L, Young ME, Birchwood N (2013) Rural Breast Cancer Patients and Survivor's Perspectives using Online Health Resources. J Womens Health, Issues Care 2:6.

doi:http://dx.doi.org/10.4172/2325-9795.1000124

on the Internet and consumer health information, Powell, et al. concluded that "very few studies have considered how consumers use what they find" [23] and that, despite the publication of thousands of papers related to online health information, little research has been published that explores the reasons consumers seek health information online or the outcomes of online health information searches [24]. This argument has been supported specifically in the area of online cancer information use [24]. Fogel specifically argues the need for more "process research" examining "the processes used by individuals to use this Internet medium", noting that, thus far, there has been no such research among breast cancer patients [25].

The purpose of this study is to investigate online health information searches of rural breast cancer patients and survivors by observing their online information search procedures. The findings will inform the development of interventions to increase rural breast cancer patients' and survivors' abilities to use the Internet as a health information source. Secondly, it will enable website providers to tailor consumer-focused sections of their websites to better address the needs and preferences of breast cancer patients. When healthcare providers understand the thought process of their patients, they are better prepared to navigate the patient-provider relationship that is ever changing.

\section{Methods}

When studying a concept as complex as human thought processing, using qualitative research adds significant value. Little is known about the process rural breast cancer patients and survivors use to search the Internet for health information. Qualitative research is particularly useful for building theory and framework in these situations. This pilot study used a think-aloud approach to analyze the Internet search strategies of participants. Think-aloud protocols introduce a task and have participants work through the task in their natural environment while researchers note the process [26]. Think-aloud interviews allow for particular depth in understanding decision-making but the interviewer must be careful not to guide or influence participants throughout the process.

Five breast cancer patients $(n=3)$ and survivors $(n=2)$ agreed to participate in the IRB approved study. Patients were in the second and third stage of breast cancer. Survivors were defined as those who are currently in remission. The participants were all female, English-speaking, white $(\mathrm{n}=4)$ or African American $(\mathrm{n}=1)$ ranging in age from 45 to 67 years old. The sample is representative of breast cancer patients given older white women develop breast cancer more often than African-Americans. Participants were recruited through a regional teaching hospital by an oncologist and two oncology social workers. All recruitment materials met HIPAA regulations to protect the patient's privacy. After eligibility screening (over the age of 21, prior Internet use, English-speaking), women were contacted to arrange a date, time and place to conduct the think-aloud interview.

Interviews were conducted by two researchers at participants' homes $(n=3)$ and the local library $(n=2)$ by where high-speed Internet access was available. After informed consent, the participants sat at the computer with the researchers nearby to provide directions and record actions. The interview guide included three tasks; including a specific search (how chronic inflammation affects reoccurrence), a reenactment of previously conducted search, and a specific search within in a designated website (Aromasin within American Cancer Society's cancer.org website). After the three designated searches, participants were asked the following open-ended questions about their recommendations for Internet information search training for women newly diagnosed with breast cancer:

- Are there any websites you won't use?

- What are your favorite websites for health information?

- How did you learn to conduct online information searches?

- Do you think there would be interest among newly diagnosed breast cancer patients in Internet search training?

- What would be the best process for this training?

- Who should conduct these trainings?

Interviews lasted between 60 and 90 minutes, were digitally audio-recorded and transcribed verbatim into Microsoft Word. The interviews were analyzed using NVivo 9 to identify key themes. The data was also hand coded by the research team to organize themes.

\section{Results}

This study investigated online health information searches of rural breast cancer patients and survivors. Participants worked through the tasks described in the methods section while discussing their thought process. Rather than addressing specific research questions, investigators used the major themes to guide the organization of findings. Throughout the interviews, all participants referenced their health care provider relationship as a major influence on their online health information search and evaluation process. Researchers organized the key themes into the complexity of the provider-patient relationship (trust, dissatisfaction, sharing information, and respect) and how that relationship influences the search and evaluation process. Finally, participants offered recommendations on how to train breast cancer patients on using online information sources.

\section{The complex provider-patient relationship}

The healthcare provider team, inclusive of the oncologist, primary care doctor and nurses, working with breast cancer patients and survivors are consistently viewed as the most important sources of information. Study participants referenced their relationship with their providers throughout the think-aloud study. The patient's trust of their healthcare providers affects the way they seek, process, and evaluate online breast cancer information.

The relationship is not comprised of blind trust by the patient because some of them felt dissatisfied after their initial consultations about their breast cancer diagnosis. Patients also sought online information to compare their treatment plans with other patients. The respect for their healthcare providers and their expertise was apparent throughout the interviews. When faced with new or contradictory information, the participants shared the information with their doctors to get their opinions, as well, as with other breast cancer survivors:

Tara: "This has been more of a team effort and not just somebody dictating to me what basically is gonna happen, that I am a willing participant and that they really want me to be involved".

Pam: "I always check it with several people, not just my doctor. I've got friends that have had breast cancer, different types of breast cancer. I belong to Team Survivor of North Florida. It's a group of cancer women survivors. We talk a lot there, so. We compare notes".

In this study, participants printed information that they had 
Citation: Merten JW, Walsh-Childers K, Rodman L, Young ME, Birchwood N (2013) Rural Breast Cancer Patients and Survivor's Perspectives using Online Health Resources. J Womens Health, Issues Care 2:6.

questions about to discuss with their doctor. Several participants used email to communicate with their doctor and ask questions about information found online. Rural women were particularly grateful to be able to communicate through email with their provider because they were often geographically removed from the site.

With the progression of the Internet, providers are working with more informed, sometimes misinformed, patients. The availability of information through the Internet has presented unique challenges for providers who encounter patients who have found incomplete or erroneous information online. Providers may spend valuable consultation time correcting misinformation and potentially violate the patient's trust if the patient feels dismissed, or if the provider is not correctly treating their cancer:

Cayla: "What he was saying went along with what I researched and what I already knew. Doctors, they're smart, you tell them your symptoms and they diagnose you with A and sometimes it could be B".

Cayla recalled asking her doctor for a copy of her pathology report:

"Do you think you are going to understand it?"

She responded: "Well, not when you give it to me. I won't understand it, but, by the end of the day, I'll understand it".

She used the Internet to define terms on the report that she did not understand.

Sharon: "When I was first diagnosed, my surgeon gave me a $20 \%$ chance of making it. He is now known as Dr. Death. I'm serious! It is beneficial for physicians to know that they are not the only resource or a "god-like" resource for patients".

Some patients even looked up their doctor's published research and conference presentations. Although there was certain pride apparent in participant's who had doctors with national recognition, some of their searching was just another measure to make sure they had complete information from their doctor:

Tara: "Maybe I could find something that he's not telling me, cause they do try to make it sound not so bad".

Cayla: "I think once you've been diagnosed with something, you want to know everything there is to know. You really do. The doctors don't give you a lot of information. I did find that out".

\section{The online health information search and evaluation process}

Breast cancer patients are, without question, using the Internet to find more information about their condition. Their search process usually starts with a general search engine; Google and Yahoo were mentioned. Some participants seemed to be unclear on the difference between a web browser and search engine, which led to them using the default search engine installed on the computer. When searching for a particular breast cancer symptom, treatment or therapy, participants typed related words in the search bar and reviewed the top results on the first page. Patients were particularly fond of comprehensive sites that had enough information that they did not have to visit many websites to get their desired information:

Sharon: "Just putting whatever you're looking, like breast cancer, in a search engine and then it pulls up a list of sites and you just check them out".

Michele: "Websites that are easy to read and have a host of information, so I don't have to go from website to website searching for different things - it's all right there".

After visiting the initial results, participants had clear ideas on what websites would be considered for further use. Participants were universally turned off by websites with lots of advertisements:

Cayla: "You'll have a little section here and then advertisements on both sides. It just puts me off because to me it's just advertising type stuff and I don't want to deal with that".

The persistence and determination among participants to find satisfactory Internet information was compelling. Unequivocally, participants stated they would not stop searching until they felt they had found consistent information and what they were looking for:

Pam: "I am the type of person that will dig until I'm satisfied. Let's see how do I say that? 'till I get my answer".

Michele: "I'll look until everything I'm finding is totally consistent, even if I've done it four, five or more times and if I'm not finding anything new about it".

Participants were also loyal to certain websites, notably Mayo Clinic and breastcancer.org when searching for reliable breast cancer information. When searching for other health information, participants evaluated WebMD as a good website:

Tara: "Usually when I look for stuff, I try to look at who wrote it and if it's actually from a cancer center. I usually use a lot of Mayo, from the Mayo Clinic. Anything that says Mayo [Clinic], I pretty much go there. They're just like this big umbrella of knowledge".

Pam: "I like Mayo [Clinic] because I don't want a person's opinion. I want to see statistics. That's what I want to see".

Michele: "It makes it a lot easier [to have one reliable site]. Breastcancer.org is the website to go to. And it gives you everything. It's got surgery. It's got chemo. It's got it all. And you just click on the topic that you're looking for and it just tells you. It gives you explanations. It's easy to read".

They acknowledged there is a learning component to learning how to successfully navigate the Internet. The majority of participants noted they spent hours of time researching their condition. Trial and error plays into the experience:

B"I haven't really had a whole lot of trouble. Just kind of bumbling and stumbling on my own".

In addition to more information about their condition, patients used the Internet to search for alternative treatments, clinical trials, experimental studies and second opinions. One participant struggled with lethargy and mental confusion after chemotherapy. Her physician was unable to diagnosis her conditions based on her description of the symptoms so she took to the Internet:

Cayla: "The reason why my doctor, was not familiar with it is because, up until now, most women died from the breast cancer and now you're having survivors and now you're seeing the long term effects and this is one of the effects. And now there are studies that back up what I had been saying for years".

Complimentary medical approaches such as yoga, meditation and acupuncture are supported by most preeminent cancer centers. Alternatives means of cancer treatment that are not medically proven have created a sore spot between providers and patients. Patients are 
Citation: Merten JW, Walsh-Childers K, Rodman L, Young ME, Birchwood N (2013) Rural Breast Cancer Patients and Survivor's Perspectives using Online Health Resources. J Womens Health, Issues Care 2:6.

seeking hope and are often scared of the ill effects from traditional treatments like mastectomies, chemotherapy and radiation therapy. Most respondents in this study said online information supplemented, rather than replaced, provider recommendations. The Internet has a lot of sites offering alternatives treatments that intrigue patients and the situation is exacerbated when celebrities endorse holistic treatments:

Sharon: "I just want to know what's going on and what's out there, because now you have new cancer centers coming up where they're advocating no chemotherapy. Cancer Centers of America is doing something totally different. Maybe, I don't want to do the Chemotherapy route; I want to do this route".

Pam: "I look at Suzanne Somers who did not want to do Chemo and her cancer is gone. She used a holistic approach".

Participants were notably sophisticated in their desire for recent clinical trials and experimental studies offering better treatment and survival outcomes. Peer-reviewed journals were of particular interest but some women were unable to access the full article if they didn't have access through a local university. Websites ending in .org or .gov were noted as reliable, however, the National Cancer Institute website was noted as overwhelming and confusing. The women were also savvy in basic Internet site evaluation techniques of looking for the date, references and funding source. Their instincts rather than formal training guided these evaluation techniques.

Tara: "I just want to know what's going on and what's out there, because now you have new cancer centers coming up where they're advocating no chemotherapy. Cancer Centers of America is doing something totally different. Maybe, I don't want to do the Chemotherapy route; I want to do this route".

Pam: "I look at Suzanne Somers who did not want to do Chemo and her cancer is gone. She used a holistic approach".

Social support is a huge part of the breast cancer treatment and survival journeys. One of the Internet's biggest successes has been the ability to connect people all over the world with similar interests, concerns and experiences. These relationships serve as sources of hope, support and encouragement:

Sharon: "There was one forum that gave me hope, where some lady had had the same, exact same thing, the same. She might have been a year older, younger, maybe than me. The exact same thing. And she lived to be in her nineties and died of something totally different. So, (with laughter) I haven't been back looking at it since".

Tara: "By talking with the other women who were there going through it, they taught me chemotherapy weren't just my vision of, you know, a hundred pounds and just "death come take me any day". It was totally different. And I was like OK, I can do this".

Patients seek forums and blogs with other breast cancer patients and survivors to look for others who have a similar condition. The descriptive norms, people's perception of what is usually done in a particular situation, present another critical communication moment for providers who need to explain the technical diagnosis may be the same between patients, but all patients have different medical histories.

\section{Recommendations for future patient training}

Participants expressed support for nurses providing Internet search training for newly diagnosed breast cancer patients. Librarians and other non-medical professional would not have the same level of credibility as a nurse or doctor. Several patients noted the importance of having a survivor or a medical professional with a loved one with breast cancer facilitate the training, particularly females with an empathetic temperament and a background in education. Participants noted that some doctors might make them nervous during the training, which is another reason to use a nurse as a trainer:

Sharon: "Nurses are probably the best teachers in many respects. I don't think doctors have time to do it".

Tara: "I listen to women before I listen, maybe, to others".

Cayla: "I think the nurses, you know, but will a doctor pay a nurse in an office or something, just to do education. Now, that's the thing, health care needs to change their thinking. Compliance might improve if we had more education on a one-to-one level but it's not built into our system as it is now".

The sensitivity and unique relationship between patient and provider cannot be ignored. When treating such a delicate and lifethreatening condition such as breast cancer, an entire medical team is often deployed to develop and deliver the treatment program. This kind of coordinated and comprehensive care creates a potentially different healthcare experience from the traditional, often fragmented and often hurried medical system.

Participants were keenly aware of the differences in the quality of their care in comparison to other non-breast cancer related care they or their loved ones experienced:

Sharon: "I find it very different with the cancer people. They seem to want questions. Call us at any time. They make you feel very comfortable about it. So, I guess I do feel that in that aspect of medicine they've got what people need and they'll spend the time with you.

It's not like they're trying to rush people in and rush people out just for the money".

As with many chronic diseases suffers, rural breast cancer patients and survivors feel a kinship with those going through the same experience. The kinship factor is important because those who have experienced breast cancer are best suited for empathizing and training newly diagnosed patients.

\section{Discussion}

Existing research demonstrates that breast cancer patients and survivors are actively using the Internet to find further information about their condition, research treatments, and find social support. This pilot study was designed to study in greater detail how rural women conduct these searches. This study design, with in depth think-aloud interviews, revealed the complexity of the provider patient relationship and the effect of that relationship on Internet information seeking. All patients use the Internet to research their condition; however, those with trusting relationships with their healthcare team will loop back to their provider to verify and discuss information found online. Patients with less trusting relationships with their healthcare team will verify information with trusted others rather than the health care team. This dynamic is important for healthcare providers working with breast cancer patients because they have the opportunity on the front end of care, at diagnosis, to establish trust with the breast cancer patient and coach them on conducting effective Internet searches.

Health care providers also face the challenge of losing breast 
Citation: Merten JW, Walsh-Childers K, Rodman L, Young ME, Birchwood N (2013) Rural Breast Cancer Patients and Survivor's Perspectives using Online Health Resources. J Womens Health, Issues Care 2:6.

cancer patients to alternative treatments. Traditional medically proven breast cancer treatments such as chemotherapy, surgery and radiation are known to be challenging, invasive, and uncomfortable to endure. When in the darkest times of traditional treatments, there is evidence that patients may use the Internet to seek alternative therapies to alleviate the pain and suffering. Patients are also enabled to seek alternative treatments when celebrities and notable public figures tout their holistic recoveries. Healthcare providers with trusting relationships with their patients can train them to improve their evaluation of Internet websites promoting unproven treatments while having an open conversation about efficacy of various treatment options.

The importance of trust within the provider-patient relationship emerged as a core theme of this analysis. The health care provider is the preferred source of information for patients. However, other studies have found that disenchantment occurs when patients discover the information given to them is not evidence-based practice; and there is a lack of clinical expertise and informational support from their providers [27]. Patients use the Internet to gain information to temper the feeling of disenchantment and exercise power by influencing and controlling their care.

Most respondents in this study said online information supplemented, rather than replaced, provider recommendations. On the other hand, a large scale study in 2002 found that about $18 \%$ of respondents reported that they had used online information to diagnose or decide how to treat a medical condition without consulting their doctor [28]. Similar studies have found social norms among breast cancer patients have been changed by the increase in Internet use [29]. Among patients newly diagnosed with all types of cancer, research has demonstrated that patients view the Internet as a "powerful information tool" and that, over time; those who sought online cancer information reported greater self-efficacy in terms of participating in treatment decisions, asking their physicians questions and sharing concerns.

In this study, participants were also clear in their desire for websites with minimal advertisements and comprehensive information. Patients were competent in identifying reputable websites associated with major cancer centers, hospitals, breast cancer advocacy groups, and research universities. This discovery provides rationale for these organizations to collaborate to provide a comprehensive resource list of websites deemed reliable, accurate, current and research-based. Additionally, website designers should heed the advice to minimize distracting advertisements. Patients were particularly interested in clinical trials and research studies for new treatments and cancer treatment providers should strive to provide robust research information on their websites. Breast cancer patients and survivors remain unfailingly hopeful that a cure will be discovered.

Even with the insightful findings, this study is limited because of the relatively small number of participants. However, the thinkaloud research style is best suited for smaller sample sizes to allow for robust exploration of participants' perspectives. The findings from this pilot work will allow investigators to better target their research questions in future work. Generalizability may present another limitation given findings may not apply to other health conditions because of the nature of the study design. Breast cancer patients and survivors may not generalize to other patients because breast cancer is a deeply personal experience with a remarkably supportive healthcare infrastructure. Beyond the treatment realm, breast cancer has received national attention through the efforts of the Susan G. Komen Foundation and other breast cancer advocacy groups. It is "vogue" for people, organizations, and businesses to support breast cancer research efforts and awareness through fundraising, events, and merchandising.

It does stand to reason that regardless of the unique circumstances associated with breast cancer, people facing disease will turn to the Internet to learn more about their condition. Rural breast cancer patients and survivors value the relationship with their provider team, appreciate the ability to communicate electronically rather than having to drive long distances for an appointment, and desire basic Internet search training early in their diagnosis. Internet usage has soared by people of all ages, races and socioeconomic level [30] and the reported rates of usage for breast cancer information seeking has risen accordingly. Additionally in the late 2000s, the interactive component of social media had begun to take shape and will further change the health information landscape. The Internet continues to change the information gathering behaviors of women with breast cancer. Providers must acknowledge those who have obtained information from the Internet and educate them on effective Internet information evaluation. This study beseeches healthcare providers to carve out a few minutes of their time with the patients to recommend reputable websites and train patients to conduct effective Internet information searches.

\section{References}

1. Deifenbach MA, Dorsey J, Uzzo RG, Hanks GE, Greenburg RE et al. (2002) Decision-making strategies for patients with localized prostate cancer. Semin Urol Oncol 1: 55-62.

2. Czaja SJ, Sharit J, Nair SN (2008) Usability of the Medicare health web site. JAMA 300: 790-792.

3. Lebo $\mathrm{H}$. The UCLA internet report: Surveying the digital future. Year three University of California Web site.

4. AIGhamdi KM, Moussa NA (2012) Internet use by the public to search for health-related information. Int J Med Inform 81: 363-373.

5. Fox S. The online health care revolution: How the web helps Americans take better care of themselves. The Pew Internet \& American Life Project.

6. Eysenbach G, Powell J, Kuss O, Sa ER (2002) Empirical studies assessing the quality of health information for consumers on the world wide web: a systematic review. JAMA 287: 2691-2700.

7. Mayo Clinic. Breast Cance

8. National Cancer Institute. SEER Stat Fact Sheets

9. American Cancer Society. What are the key statistics about breast cancer.

10. Fogel J, Albert SM, Schnabel F, Ditkoff BA, Neugut Al (2002) Use of the Internet by women with breast cancer. J Med Internet Res 4: E9.

11. Mills ME, Davidson R (2002) Cancer patients' sources of information: use and quality issues. Psychooncology 11: 371-378.

12. Larkin M (2000) Online support groups gaining credibility. Lancet 355: 1834.

13. Lacroix EM. Health topics most hit March 2010

14. Berland GK, Elliott MN, Morales LS, Algazy JI, Kravitz RL, et al. (2001) Health information on the Internet: accessibility, quality, and readability in English and Spanish. JAMA 285: 2612-2621.

15. Arroyo B, Tillinghast DS (2009) Information Needs and Self-Efficacy: Internet Use by Women with Breast Cancer. Soc Mar Q XV:102-117.

16. Muhamed M, Afshari M, Mohamed NA (2011) Internet use and breast cancer survivors. TOJET: The Turk J Ed Tech 10: 241-247.

17. Ellery PJ, Vaughn W, Ellery J, Bott J, Ritchey K, et al. (2008) Understanding internet health search patterns: An early exploration into the usefulness of Google Trends. J Commun Health 1: 441-456. 
Citation: Merten JW, Walsh-Childers K, Rodman L, Young ME, Birchwood N (2013) Rural Breast Cancer Patients and Survivor's Perspectives using Online Health Resources. J Womens Health, Issues Care 2:6.

18. Gustafson DH, McTavish FM, Stengle W, Ballard D, Jones E, et al. (2005) Reducing the digital divide for Low-Income Women with Breast Cancer: A Feasibility Study of a Population-Based Intervention. J Health Commun 10 173-193.

19. Bettencourt BA, Schlegel RJ, Talley AE, Molix LA (2007) The breast cance experience of rural women: a literature review. Psychooncology 16: 875-887.

20. Wilson F, Baker L, Brown-Syed C, Gollop C (2000) An analysis of the readability and cultural sensitivity of information on the National Cancer Institute's Web site: CancerNet. Oncol Nurs Forum 27: 1403-1409.

21. Williamson K (2005) Where one size does not fit all: understanding the needs of potential users of a portal to breast cancer knowledge online. $\mathrm{J}$ Health Commun 10: 567-580.

22. Peterson G, Aslani P, Williams KA (2003) How do consumers search for and appraise information on medicines on the Internet? A qualitative study using focus groups. J Med Internet Res 5: e33.

23. Powell JA, Lowe P, Griffiths FE, Thorogood M (2005) A critical analysis of the literature on the Internet and consumer health information. J Telemed Telecare 11 Suppl 1: 41-43.
24. Eysenbach G (2003) The impact of the Internet on cancer outcomes. CA Cancer J Clin 53: 356-371.

25. Fogel J (2003) Internet use for cancer information among racial/ethnic populations and low literacy groups. Cancer Control 10: 45-51.

26. Cotton, DRE, Gresty KA (2007) The rhetoric and reality of e-learning: Using the think-aloud method to investigate student use of an online resource. Assess and Eval in Higher Ed 32: 583-600.

27. Dolce MC (2011) The Internet as a source of health information: experiences of cancer survivors and caregivers with healthcare providers. Oncol Nurs Forum 38: 353-359.

28. Fox S, Rainie L (2002) E-patients and the online health care revolution. Physician Exec 28: 14-17.

29. Zikmund-Fisher BJ, Windschitl PD, Exe N, Ubel PA (2011) 'I'll do what they did": social norm information and cancer treatment decisions. Patient Educ Couns 85: 225-229.

30. Fox S. Cancer 2.0; A summary of recent research. Washington, DC: The Pew Internet \& American Life Project.

\section{Author Affiliations}

${ }^{1}$ Department of Public Health, University of North Florida, Jacksonville, Florida, USA

${ }^{2}$ College of Journalism and Communication, Florida, USA

${ }^{3}$ Department of Behavioral Science and Community Health, University of Florida, Gainesville, Florida, USA

\section{Submit your next manuscript and get advantages of SciTechnol} submissions

* 50 Journals

* 21 Day rapid review process

* 1000 Editorial team

* 2 Million readers

* Publication immediately after acceptance

* Quality and quick editorial, review processing

Submit your next manuscript at • www.scitechnol.com/submission 